\title{
Mechanisms of aggregation inhibition by aspirin and nitrate-aspirin prodrugs in human platelets
}

\author{
Shona Harmon a, Iwona Inkielewicz-Stepniakc, Michael Jonesa, Mark Ledwidge ${ }^{\mathrm{b}}$, \\ Maria Jose Santos-Martinez ${ }^{\mathrm{a}}$, Carlos Medinaa, Marek W. Radomski and John F. Gilmer ${ }^{\mathrm{a}}$

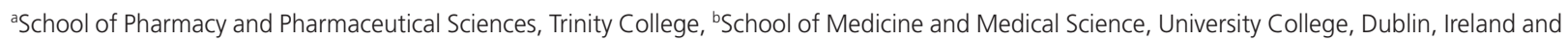 \\ 'Department of Medicinal Chemistry, Medical University of Gdansk, Gdansk, Poland
}

\section{Keywords}

aggregation; aspirin; carboxylesterase activity; cholinesterase activity; platelet

\section{Correspondence \\ John F Gilmer, School of Pharmacy and Pharmaceutical Sciences, Trinity College, \\ Dublin 2, Ireland. \\ E-mail: gilmerjf@tcd.ie}

Received March 8, 2011

Accepted September 22, 2011

doi: $10.1111 / j .2042-7158.2011 .01380 . x$

\begin{abstract}
Objectives Aspirin is the mainstay of anti-platelet therapy in the secondary prevention of cardiovascular disease. However, problems with aspirin safety and resistance demand clinical strategies based on multiple pharmacological approaches. Prodrugs of aspirin may offer beneficial effects in terms of gastro-intestinal safety and multiple pharmacological approaches. However, the pharmacological profile of aspirin prodrugs in human platelets has not been completed yet. We aimed to compare the effects of aspirin and prodrugs of aspirin (1-5) on human platelet aggregation stimulated by ADP and collagen and associated receptor expression (GPIIb/IIIa and P-selectin) in platelet-rich plasma (PRP) and washed platelets (WP).

Methods As aspirin is released from prodrugs following esterase hydrolysis we studied the expression and activity of butyrylcholineterase $(\mathrm{BuChE})$ and carboxyesterase (CE) in plasma and platelets. The mechanism of prodrug-induced platelet aggregation inhibition was explored by studying the effects of plasma and purified human BuChE on aggregation. Finally, the relative contribution of nitric oxide $(\mathrm{NO})$ bioactivity to nitrate-containing prodrugs of aspirin-induced inhibition of aggregation was determined using $1 \mathrm{H}-[1,2,4]$ oxadiazolo[4,3-a] quinoxalin1-one (ODQ,) a selective inhibitor of the soluble guanylyl cyclase.

Key findings ST0702, 2, a nicotinic acid-aspirin codrug was equipotent with aspirin with respect to inhibition of collagen-induced platelet aggregation. Compound 4, a NO releasing aspirin was the most potent inhibitor of ADP-induced platelet aggregation, an effect partially reversed by ODQ. The platelet inhibitory effects of aspirin prodrugs were time-dependent as the maximal inhibitory effects against collagen-induced aggregation were achieved by aspirin at $2 \mathrm{~min}, 1$ at $5 \mathrm{~min}$ and ST0702 at $15 \mathrm{~min}$. The aspirin prodrugs were significantly less potent in WP than in PRP and the reverse was true of aspirin. In the presence of complete BuChE inhibition in PRP, there was almost complete loss of aspirin prodrug, but not aspirin anti-aggregatory activity. Interestingly, CE activity was observed in WP and platelet lysate with pNPA substrate. Accordingly, $\mathbf{1}$ and ST0702 retained $50 \%$ and $100 \%$ anti-aggregatory activity at maximal concentrations in WP, which was attenuated in the presence of esterase inhibitor phenylmethylsulphonyl fluoride.

Conclusions The inhibitory effect of aspirin prodrugs in PRP is due to prodrug activation by BuChE. In contrast, the platelet-inhibitory effects of aspirin prodrugs in WP may be mediated through the activity of platelet CE. Compound 4, a NO-containing aspirin prodrug, may exert dual inhibitory effects in platelets. Thus, aspirin prodrugs effectively inhibit human platelet aggregation and as such may be an alternative to conventional aspirin.
\end{abstract}




\section{Introduction}

True aspirin ester prodrugs are compounds designed to undergo processing in human blood, producing aspirin. ${ }^{[1]}$ They are of interest primarily because they are predicted to be less toxic to the gastro-intestinal tract than aspirin. Aspirin's acid group is associated with its topical irritancy, with ion trapping and with cyclooxygenase (COX)-1/COX-2 inhibition. ${ }^{[2,3]}$ Esterification blunts the topical irritancy effect, suppresses ion trapping and is predicted to abolish local COX inhibitory effects. Aspirin prodrugs also hold promise for addressing some of the efficacy deficits of the parent drug. Aspirin fails to prevent atherothrombotic events in the majority of patients with symptomatic atherothrombotic disease $(75-80 \%){ }^{[4,5]}$ This is a complex problem that is partly due to poor compliance (which is linked to intestinal toxicity) but it is also a reflection of the multi-factorial nature of cardiovascular disease which demands multiple pharmacological responses.

Recently, we reported on the first 'true' aspirin prodrug, isosorbide-2-aspirinate-5-salicylate, $\mathbf{1}$ (Figure 1). ${ }^{[6]}$ This is activated very rapidly in solutions containing human plasma butyrylcholinesterase (BuChE, EC 3.1.1.8) because of a highly specific interaction with BuChE. Compound 1 undergoes parallel processing in plasma, generating isosorbide disalicylate (15\%) (Figure 1b). Normally aspirin esters are processed exclusively along this route, ${ }^{[1]}$ which abolishes platelet inhibitory properties. By taking account of esterase preferences it was possible to design hybrid compounds able to release a second active moiety relevant to cardiovascular disease. ${ }^{[7]}$ In human plasma solution, ST0702 releases aspirin (30-45\%) and nicotinic acid (niacin). Nicotinic acid increases high-density lipoprotein cholesterol (HDL) and reduces low-density lipoprotein cholesterol and triglycerides. ${ }^{[8,9]}$ Moreover, it is the pharmacological agent of choice for reduction of elevated lipoprotein (a), a new treatment target in cardiovascular disease. ${ }^{[10]}$ The nitrate hybrids (3-5) were designed to release an organic nitrate and aspirin (nitric oxide (NO)-aspirin). NO is gastroprotective through multiple mechanisms: by promoting blood flow, removing toxins and stimulating mucus secretion and angiogenesis. $\mathrm{NO}$ is also a potent vasodilator and it inhibits platelet and monocyte adhesion and platelet aggregation. ${ }^{[11-13]}$ The combination with aspirin has been extensively investigated with interesting outcomes that support the gastro-protective proposition. ${ }^{[14-16]}$

Aspirin ester prodrugs consistently exhibit greater inhibition of platelet aggregation in vitro than expected based on aspirin to salicylate production in plasma and blood. ${ }^{[17]} \mathrm{Com}-$ pound $\mathbf{1}$, for example, is a significantly more potent inhibitor of platelet aggregation than aspirin in whole blood in response to arachidonic acid and in platelet-rich plasma (PRP) stimulated with collagen $(5 \mathrm{mg} / \mathrm{ml})$; it is also more efficacious than aspirin with respect to stimulation by adenosine diphosphate (ADP) $(3 \mu \mathrm{M}) .^{[6,7]}$ The greater than expected potency of true aspirin prodrugs is a puzzling and potentially useful property.

The purpose of this paper is to report on the first pharmacological investigation into the platelet inhibitory properties of isosorbide-based aspirin prodrugs. We examined the relative potency of the compounds as inhibitors of aggregation in PRP and washed platelets (WP) (where BuChE is absent); the involvement of platelet receptors; the effect of BuChE and esterase inhibitors on potency and efficacy; the relative roles of aspirin and NO in the effects of 3-5; the time course for activation and platelet inhibition; and the role of platelet esterases in aspirin prodrug activation.

\section{Materials and Methods}

\section{Reagents}

All reagents were purchased from Sigma-Aldrich (Dublin, Ireland) unless otherwise stated. Collagen and ADP were obtained from Chronolog (Havertown, USA). Allophycocyanin (APC)-conjugated monoclonal antibody against highaffinity GPIIb/IIIa (PAC-1-APC) and APC-conjugated monoclonal antibody against human platelet $\mathrm{P}$ selectin (CD62P) were purchased from BD Biosciences (Oxford, UK). Human polyclonal anti-CES 1 and CES 2 antibodies were purchased from Sigma-Aldrich (Dublin, Ireland). Wild Type BuChE (EC 3.1.1.8) was a kind gift from Oksana Lockridge, University of Nabraska, USA. Human liver and intestinal microsomes, BD Gentest, were obtained from BD Biosciences (Woburn, MA, USA). Test compounds were dissolved in dimethyl sulfoxide (DMSO), then diluted in PRP or WP to give a final concentration not more than $0.25 \%$ DMSO, which pilot studies had determined not to affect platelet aggregation. No precipitation of test compound was observed following dilution.

\section{Preparation of human platelets}

Blood was collected from fully consented healthy volunteers at the School of Pharmacy and Pharmaceutical Sciences, Trinity College, Dublin, who had not taken any drugs known to affect platelet function for at least 14 days before the study. The study was approved by the Trinity College Dublin Ethics Committee. PRP and WP $\left(2.5 \times 10^{8}\right.$ platelets $\left./ \mathrm{ml}\right)$ were prepared from blood as previously described. ${ }^{[18]}$ Briefly $36 \mathrm{ml}$ whole blood was collected into $4 \mathrm{ml}$ of $3.15 \%$ sodium citrate; this was centrifuged at $250 \times \mathrm{g}$ for $20 \mathrm{~min}$ (with gentle acceleration and deceleration). At this point PRP, which had separated from white blood cells and red blood cells, was gently removed. When WP were required this PRP was centrifuged at $700 \mathrm{~g}$ for $10 \mathrm{~min}$ (with gentle acceleration and deceleration) in the presence of prostacyclin. The platelet-poor plasma 
(a)

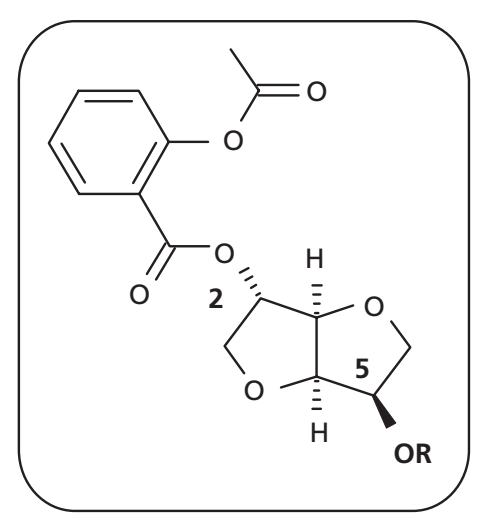

$\mathbf{R}=$<smiles>O=C(I)c1ccccc1O</smiles>

$\mathbf{R}=$<smiles>O=C(I)c1ccccc1CO[N+](=O)[O-]</smiles><smiles>CC(=O)c1cccnc1</smiles>

2, ST0702<smiles>O=C(I)c1ccc(CO[N+](=O)[O-])cc1CO[N+](=O)[O-]</smiles>

4 5

(b)<smiles>CCCCO[C@H]1CO[C@H]2[C@H](OC(=O)c3ccccc3O)CO[C@H]12</smiles><smiles>COC(=O)c1ccccc1O</smiles>

Isosorbide-2,5-disalicylate

$15-20 \%$<smiles>CC(=O)Oc1ccccc1C(=O)O</smiles>

$80-85 \%$
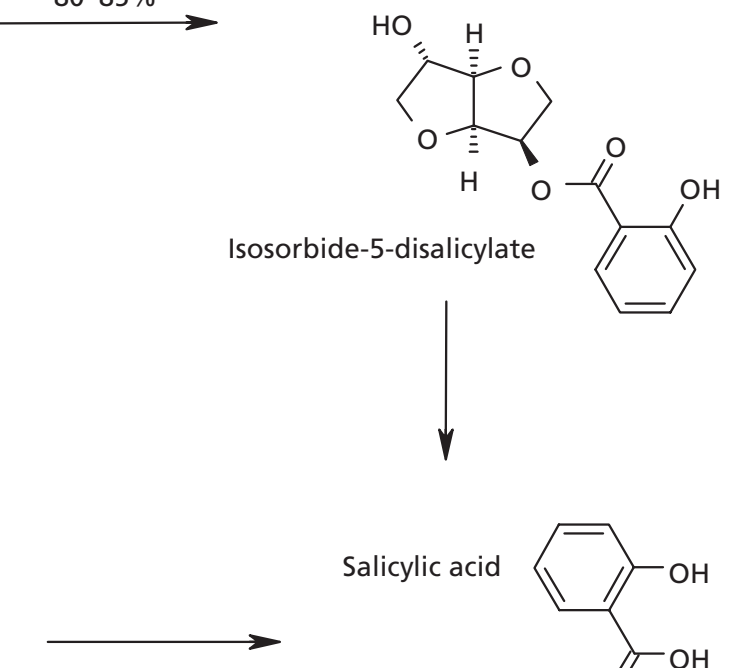

Salicylic acid<smiles>O=C(O)c1ccccc1O</smiles><smiles></smiles>

Figure 1 (a) Structural formulae of aspirin prodrug test compounds. (b) Metabolic routes of 1 in human plasma butyrylcholineterase (BuChE) solution generating aspirin and salicylate ester compounds. 
(PPP) was removed and the platelet pellet was washed three times with Tyrode's buffer, before being re-suspended in Tyrode's buffer to a concentration of $2.5 \times 10^{8}$ platelets $/ \mathrm{ml}$.

\section{Platelet aggregation and its inhibition by aspirin prodrugs}

Platelet aggregation was measured by light aggregometry as previously described. ${ }^{[19-21]}$ Briefly, PRP and WP samples $\left(2.5 \times 10^{8} / \mathrm{ml}\right)$ were placed in an eight-channel Platelet Aggregation Profiler Model PAP-8E and incubated for $10 \mathrm{~min}$ at $37^{\circ} \mathrm{C}$, with stirring at $900 \mathrm{rpm}$, before the addition of aggregating agents. Aggregation was initiated by the addition of agonists, and monitored by Aggro-Link software for at least $6 \mathrm{~min}$. For experiments using inhibitors, aggregation was initiated after $10 \mathrm{~min}$ pre-incubation with test compounds.

To study the aggregatory potency of ADP, concentrationresponse $(0.3-10 \mu \mathrm{M})$ curves were generated. Collagen at different concentrations $(2-5 \mu \mathrm{g} / \mathrm{ml})$ was also used to induce platelet aggregation. Sumbmaximal concentrations of agonists (i.e. the concentrations that gave approximately $95 \%$ of the maximal aggregation) were used to study the effects of inhibitors of aggregation. Aspirin and aspirin prodrugs were incubated for various intervals before addition of aggregating agents. Results were expressed as percentage changes in maximal light transmission, with 100\% representing light transmission of platelet medium alone.

\section{Investigation of the role of plasma butyrylcholinesterase in activation of compound 1}

To study the involvement of plasma BuChE in the activation of 1 , purified BuChE $(3 \mathrm{U} / \mathrm{ml})$ was incubated with WP for $5 \mathrm{~min}$ in the aggregometer with stirring at $900 \mathrm{rpm}$ before the addition of $\mathbf{1}$, which was incubated with the WP for a further $10 \mathrm{~min}$, before the addition of collagen $(5 \mu \mathrm{g} / \mathrm{ml})$.

\section{Effect of physostigmine (eserine) on platelet inhibitory activity of prodrugs}

Physostigmine (in DMSO, $10 \mu \mathrm{M}$, giving a final concentration $\leq 0.25 \%$ DMSO, which pilot studies had determined not to affect platelet aggregation) was pre-incubated with PRP or WP for $5 \mathrm{~min}$ in the aggregometer with stirring at $900 \mathrm{rpm}$ before the addition of test compounds (1-5). These were incubated in PRP or WP for a further $10 \mathrm{~min}$ before the addition of an agonist ( $10 \mu \mathrm{M}$ ADP or $5 \mu \mathrm{g} / \mathrm{ml}$ collagen) to induce platelet aggregation.

\section{Effect of 1H-[1,2,4]oxadiazolo[4,3- a]quinoxalin-1-one on bioactivity of prodrugs}

1H-[1,2,4] Oxadiazolo[4,3-a]quinoxalin-1-one (ODQ, dissolved in $100 \%$ DMSO, used at a final concentration of $10 \mu \mathrm{M}$, which gave a final concentration not more than $0.25 \%$ DMSO) was pre-incubated with PRP or WP for $5 \mathrm{~min}$ in the aggregometer with stirring at $900 \mathrm{rpm}$ before the addition of test compounds (1-5), which were incubated in PRP or WP for a further $10 \mathrm{~min}$ before the addition of an agonist (10 $\mu \mathrm{M} \mathrm{ADP}$ or $5 \mu \mathrm{g} / \mathrm{ml}$ collagen) to induce platelet aggregation.

\section{Effect of phenylmethylsulphonylfluoride on activity of ST0702 in washed platelets}

Phenylmethylsulphonylfluoride (PMSF) 20, 50 and $100 \mu \mathrm{M}$ dissolved in $\mathrm{EtOH}(\leq 0.2 \% \mathrm{EtOH}$, which pilot studies had determined not to affect platelet aggregation) was preincubated in WP in the aggregometer for 5 min with stirring at $900 \mathrm{rpm}$ before the addition of test compound ST0702 to the WP, which was further incubated for $10 \mathrm{~min}$ before the addition of collagen $(2 \mu \mathrm{g} / \mathrm{ml})$ to induce platelet aggregation.

\section{Activity of plasma esterase}

\section{Cholinesterase activity}

PRP, WP samples $\left(2.5 \times 10^{8}\right.$ platelets $\left./ \mathrm{ml}\right)$, lysed WP samples and PPP were analysed for the presence of BuChE activity, according to the method of Ellman, with some modifications. ${ }^{[22]}$ S-butyryltiocholine iodide (BTCI) at $1 \mathrm{~mm}$ in phosphate buffer $\mathrm{pH} 8.0$ at $37^{\circ} \mathrm{C}$ was used as substrate to measure the activity of BChE in WP, PRP, PPP and in WP lysed with Triton X-100. Combined acetyl cholinesterase (AchE) and BChE activity was measured with $1 \mathrm{~mm}$ acetlythiocholine iodide (ATCI). A 4- $\mu$ l volume of WP, PRP, PPP or lysed WP, Ellman's reagent (DTNB $10 \mu \mathrm{M}$ ) and phosphate buffer $\mathrm{pH}$ 8.0 were incubated in a 96 -well plate at $37^{\circ} \mathrm{C}$ for $30 \mathrm{~min}$. BTCI or ATCI was added to give a final concentration of $1 \mathrm{~mm}$ and the change in absorbance at $405 \mathrm{~nm}$ was measured over a period of $10 \mathrm{~min}$ on a plate reader.

\section{para-Nitrophenyl acetate assay}

WP, PRP, PPP or lysed WP and $50 \mathrm{~mm}$ TrisHCl pH 7.4 were incubated on a 96 -well plate at $37^{\circ} \mathrm{C}$ for $30 \mathrm{~min}$. paraNitrophenyl acetate (PNA) at a final concentration of $3 \mathrm{~mm}$ was added to the plate and the change in absorbance at $405 \mathrm{~nm}$ was measured over a period of $10 \mathrm{~min}$. NPA hydrolysis activity could be due to $\mathrm{CE}$ (EC 3.1.1.1), BuChE, acetylcholinesterase (AChE, EC 3.1.1.7) or paraoxanase/ 
arylesterase (PON, EC 3.1.8.1). To identify which esterases were involved in the hydrolysis of PNA, various inhibitors were incubated with the WP, PRP, PPP or lysed WP and $50 \mathrm{~mm}$ Tris $\mathrm{HCl} \mathrm{pH} 7.4$ for $30 \mathrm{~min}$ at $37^{\circ} \mathrm{C}$ before the addition of the PNA and the measurement of the change in absorbance at $405 \mathrm{~nm}$. Physostigmine $(100 \mu \mathrm{M})$, a cholinesterase inhibitor was used to check if BuChE/AChE played a role in the hydrolysis of PNA. Iso-OMPA, a selective BuChE inhibitor, was also used. PMSF $(10-100 \mu \mathrm{M})$ was used to determine whether serine proteases played any part in the hydrolysis of PNA by platelets. EDTA a calcium chelator was used to investigate the role played by PON esterases. BNPP, a CE inhibitor, was used to investigate whether CEs played a role in hydrolysis of PNA by platelets.

\section{Control and solvent checks}

Control experiments were performed throughout the course of each experiment to establish normal aggregation responses. Before each experiment, a sample of PRP or/and WP was incubated with $10 \mu \mathrm{l}$ of DMSO for $10 \mathrm{~min}$ at $37^{\circ} \mathrm{C}$ with stirring to ensure the solvent had no inhibitory effect on the aggregation response.

\section{Flow cytometry}

To analyse receptor expression on the surface of individual platelets and to minimize platelet activation caused by sample preparation procedures, no stirring or vortexing steps were used. The abundance of activated GPIIb/IIIa and P-selectin on the surface of platelets in the presence and absence of inhibitors was measured by flow cytometry. Platelet samples were first activated with agonists, either collagen or ADP. When platelet aggregation reached 50\% maximal light transmission the reaction was terminated by 10 -fold dilution with physiologic saline. Resting platelets were used as control. In most of the experiments, platelets were pre-incubated with inhibitors for $10 \mathrm{~min}$ before the addition of agonists. Platelet samples were then incubated in the dark without stirring for $5 \mathrm{~min}$ at room temperature in the presence of saturating concentrations $(10 \mu \mathrm{g} / \mathrm{ml})$ of P-selectin (CD62P-APC). The activated GPIIb/IIIa platelet receptors were measured using PAC-1 monoclonal antibody at the same concentration as above. PAC-1 specifically recognizes an epitope on the highaffinity GPIIb/IIIa complex of activated platelets at or near the platelet. ${ }^{[23]}$ Following incubation, samples were diluted in FACS flow fluid and analysed within 5 min using a BD FACSArray (BD Biosciences, Oxford, UK). Flow cytometry was performed on single stained platelet samples as described. ${ }^{[24-26]}$ The instrument was set up to measure the size (forward scatter), granularity (side scatter) and cell fluorescence. A two-dimensional analysis gate of forward and side scatter was drawn so as to include single platelets and exclude platelet aggregates and microparticles. Antibody binding was measured by analysing individual platelets for fluorescence. The mean fluorescence intensity was determined after correction for cell autofluorescence. For each sample, the fluorescence was analysed using a logarithmic scale. Fluorescence histograms were obtained for 10000 individual events. Data were analysed using BD FACSArray software and expressed as a percentage of control fluorescence in arbitrary units.

\section{Platelet lysate preparation}

Platelet lysates were prepared by lysing WP with $10 \times$ RIPA buffer (20 mм Tris pH 7.4, $50 \mathrm{~mm} \mathrm{NaCl,} 50 \mathrm{~mm} \mathrm{NaF,} 5 \mathrm{~mm}$ EDTA, $20 \mathrm{~mm}$ pyrophosphate, $1 \mathrm{~mm} \mathrm{Na} \mathrm{VO}_{4}, 10 \%$ Triton $\mathrm{X}$, $10 \mathrm{~mm}$ PMSF, protease inhibitor cocktail) for $1 \mathrm{~h}$ on ice with intermittent vortexing. A Bradford assay was performed to determine the protein concentration of the platelet lysate samples. Platelet lysate samples were mixed with $2 \times$ nonreducing loading buffer ( $50 \mathrm{~mm}$ tris $\mathrm{pH} 6.8,2 \%$ SDS, $0.1 \%$ bromophenol blue, $20 \%$ glycerol), or reducing loading buffer (50 mм Tris pH 6.8, 2\% SDS, $0.1 \%$ bromophenol blue, $20 \%$ glycerol, $0.5 \% \beta$-mercaptoethanol), boiled for $5 \mathrm{~min}$, centrifuged and loaded onto SDS-PAGE gels.

\section{Gel electrophoresis and immunoblot analysis}

Proteins were electrophoretically separated under nonreducing and reducing conditions as described. ${ }^{[27]}$ SDS-PAGE was performed with $7 \%(\mathrm{w} / \mathrm{v})$ separation gels at a constant voltage of $160 \mathrm{~V} / \mathrm{h}$ with the use of a Mini-Protean II gel system (Bio-Rad Laboratories, Hemel Hempstead, UK). After electrophoretic separation, proteins were transferred from the gel onto Immobilon-NC membranes, according to the method of Towbin et al., ${ }^{[28]}$ using a Bio-Rad Mini-Protean II blotting system (Bio-Rad Laboratories). Proteins separated by SDS-PAGE were transferred to nitrocellulose membranes. Nitrocellulose membranes were blocked for $1 \mathrm{~h}$ in $5 \%$ bovine serum albumin (BSA) in NT buffer (50 mm Tris pH 7.4, $170 \mathrm{~mm} \mathrm{NaCl}, 0.2 \%$ (octylphenoxy) polyethoxyethanol) (5\% BSA/NT) and incubated overnight at $4^{\circ} \mathrm{C}$ with primary antibody anti-CES2 diluted $1: 1000$, or anti-CES1 diluted $(1: 2000)$. Subsequently, immunoblots were washed twice for $10 \mathrm{~min}$ each with $100 \mathrm{ml}$ of 5\% BSA/NT per blot and incubated for $1 \mathrm{~h}$ with peroxidase-conjugated secondary antibodies at a dilution of $1: 10$ 000. After the blots had been washed twice for $10 \mathrm{~min}$ with $5 \% \mathrm{BSA} / \mathrm{NT}$ and rinsed twice with 5\% BSA/NT buffer, nitrocellulose sheets were developed by enhanced chemiluminescence. Calibration of molecular masses was based on the SDS-PAGE molecular weight standards from Bio-Rad. Liver microsomes were used as a positive control for CES1 and intestinal microsomes were used as a positive control for CES2. 
(a)

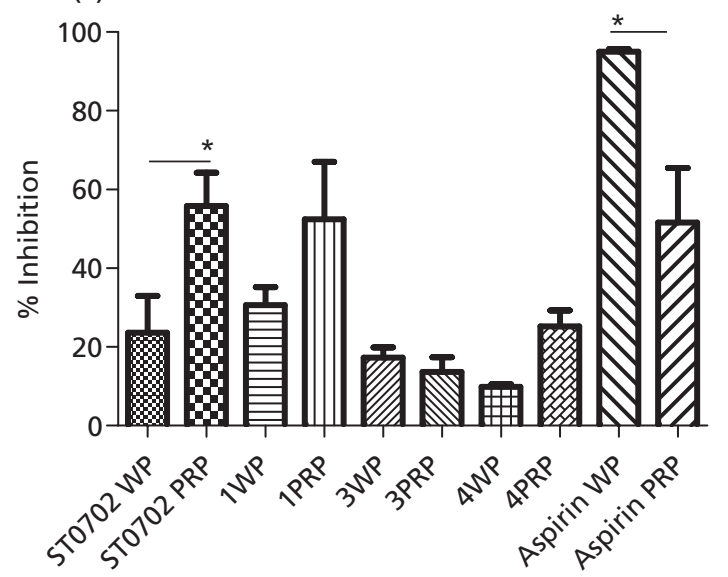

(b)

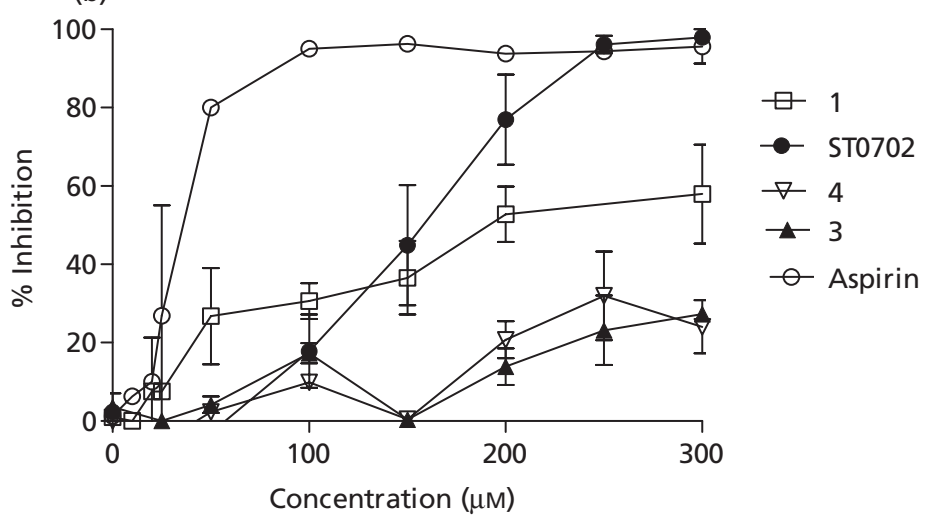

Figure 2 Inhibition of platelet aggregation in response to collagen ( $5 \mu \mathrm{g} / \mathrm{ml})$ in platelet-rich plasma (PRP) at $200 \mu \mathrm{M}$ and in washed platelets (WP) in the concentration range 10-300 $\mu \mathrm{M}\left(n=6,{ }^{*} P<0.05\right)$.

\section{Statistics}

The data were analysed using one-way analysis of variance with Bonferroni's test (GraphPad Prism 5.0, San Diego, USA). Kruskal-Wallis with appropriate post-hoc tests were used for comparing data at $n<4$. The results are expressed as mean \pm SEM of 4-6 independent experiments. Paired and unpaired Student's $t$-tests were performed, where appropriate. Statistical significance was considered when $P<0.05$.

\section{Results}

\section{Inhibition of platelet aggregation in washed platelet suspension}

As shown in Figure 2, the test compounds and aspirin caused inhibition of platelet aggregation in PRP and WP stimulated by collagen $(5 \mu \mathrm{g} / \mathrm{ml})$. The concentration estimated to cause $50 \%$ inhibition (IC50) values for inhibition of WP aggregation are presented in Table 1 . The prodrugs $\mathbf{1}-\mathbf{4}$ were significantly less potent in WP suspension than in PRP (Figure 2a). In contrast, aspirin was more potent in WP (IC50 $35 \mu \mathrm{M})$ than in PRP (IC50 $92 \mu \mathrm{M})$. This effect may be due to protein binding $\left(50 \%{ }^{[29]}\right)$ or hydrolysis; aspirin interacts with albumin partly through transacetylation ${ }^{[30]}$ which complicates measurement of free drug. Of the prodrug compounds, 2 (ST0702) was the most efficacious inhibitor of collageninduced aggregation in WP (IC50 $154 \mu \mathrm{M})$. 1 was more potent than 2 (ST0702) in this regard but less efficacious ( $50 \%$ inhibition at $500 \mu \mathrm{M}$; Figure 2b). The lack of effect of the other compounds in the absence of plasma BuChE strongly suggests that their anti-platelet effect in PRP was due to aspirin release. A role for plasma BuChE in activation of $\mathbf{1}$ was supported by the observation that its inhibitory actions
Table 1 IC50 values for the inhibition of platelet aggregation washed platelets (platelet-rich plasma) in response to collagen $(5 \mu \mathrm{g} / \mathrm{ml})$. Also shown is \% aspirin release from each of the test compounds in human plasma, the remainder producing salicylate metabolites

\begin{tabular}{lcc}
\hline Compound & $\begin{array}{l}\text { IC50 }(\mu \mathrm{M}) \text { in washed } \\
\text { platelets (platelet-rich } \\
\text { plasma, } 95 \% \mathrm{Cl})\end{array}$ & $\begin{array}{l}\text { \% Aspirin } \\
\text { release }^{\mathrm{a}}\end{array}$ \\
\hline Aspirin & $34\left(92,85-100^{\mathrm{a}}\right)$ & 100 \\
$\mathbf{1}$ & $200\left(21,17.2-23.9^{\mathrm{a}}\right)$ & $70-85$ \\
$\mathbf{S T 0 7 0 2}$ & $154(85,76-93)$ & $30-45$ \\
$\mathbf{3}$ & $>500\left(17,8.8-26.4^{\mathrm{a}}\right)$ & $60-65$ \\
$\mathbf{4}$ & $>500\left(90,79.5-100.1^{\mathrm{a}}\right)$ & $30-40$ \\
$\mathbf{5}$ & $>500(>300)$ & $<5$ \\
\hline
\end{tabular}

IC 50, concentration estimated to cause $50 \%$ inhibition of platelet aggregation. ${ }^{a}$ From Jones et al. ${ }^{[7]}$

were rescued in WP by the addition of human BuChE purified from plasma $(3 \mathrm{U} / \mathrm{ml})$. Aspirin and the aspirin prodrugs were tested as inhibitors of ADP $(10 \mu \mathrm{M})$-induced platelet aggregation in PRP $(n=6)$ (Figure $3 \mathrm{a})$. We have already reported some initial results for 1, 3 and 4 at low concentration of $\operatorname{ADP}(3 \mu \mathrm{M}) .{ }^{[7]}$ Nitrate compounds 3 and 4 were significantly more potent inhibitors of ADP $(10 \mu \mathrm{M})$-induced aggregation than 1, 2 or aspirin (Figure $3 \mathrm{a}$ and $3 \mathrm{~b}$ ). Aspirin caused consistently less inhibition of aggregation than $\mathbf{1}$ or $\mathbf{2}$ (which were similar in effect) but the difference was not significant at any single concentration.

\section{Time dependence of inhibition}

1 and $2(200 \mu \mathrm{M})$ were incubated in PRP for several time intervals $(2,5,10,20,30 \mathrm{~min})$ before addition of collagen $(5 \mu \mathrm{g} / \mathrm{ml})$ to stimulate platelet aggregation. Inhibition by $\mathbf{1}$ reached its maximum at $5 \mathrm{~min}(40 \%$ at $2 \mathrm{~min})$. No significant 


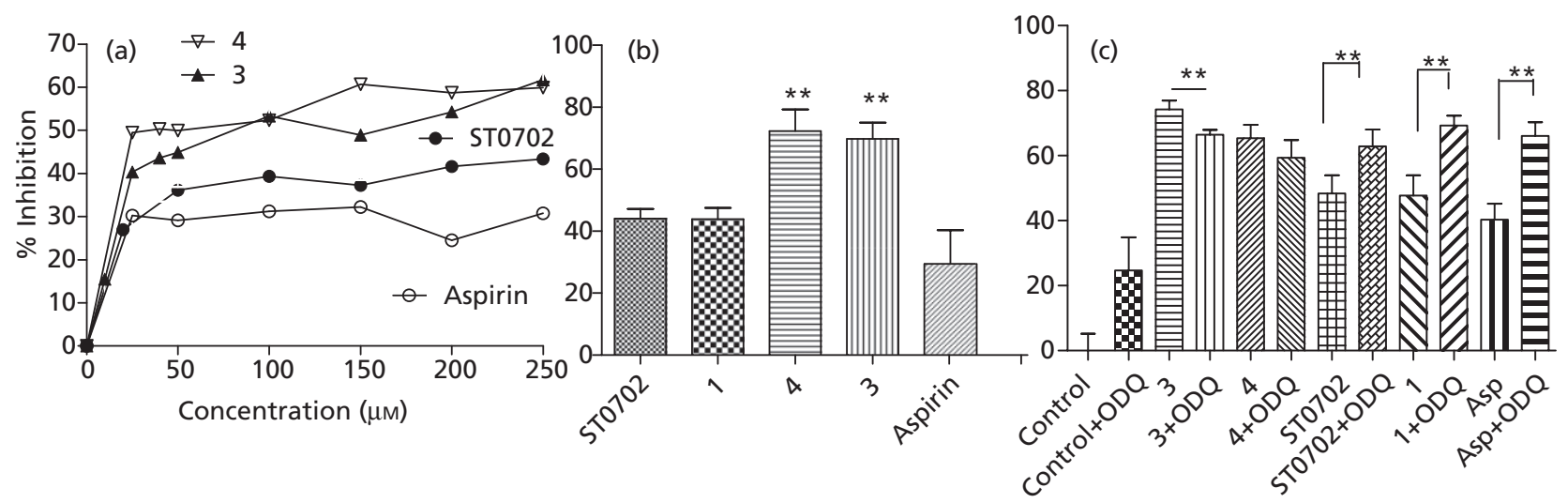

Figure 3 Inhibition of platelet aggregation in platelet-rich plasma (PRP) stimulated by adenosine diphosphate (ADP) (10 $\mu \mathrm{M}$ ). (a) The nitrate compounds $\mathbf{3}$ and $\mathbf{4}$ were significantly more potent than aspirin under these conditions. Compound $\mathbf{1}$ (data not shown) and $\mathbf{2}$, ST0702 were similar in effect on ADP-induced aggregation and more efficacious than aspirin across the test concentration range. (b) Effect of prodrugs and aspirin incubated at $100 \mu \mathrm{M}$ on ADP-induced aggregation. (c) Inhibition of ADP-induced aggregation by aspirin and aspirin prodrugs (100 $\mu \mathrm{M})$ with or without ODQ (10 $\mu \mathrm{M}$ ) Asp, aspirin; ODQ, 1H-[1,2,4]oxadiazolo[4,3-a]quinoxalin-1-one.

inhibition of platelet aggregation was observed with 2 following $0-5$ min pre-incubation. The inhibitory activity of 2 increased gradually with time and became maximal following 15-20 min pre-incubation.

\section{Effects of products of hydrolysis of the aspirin prodrugs on platelet aggregation}

Several products of plasma hydrolysis of $\mathbf{1}$ (Figure 1b) were available from a previous study that identified this compound as a true aspirin prodrug. ${ }^{[6]}$ These were tested for their effect on collagen $(5 \mu \mathrm{g} / \mathrm{ml})$-induced aggregation to see if they contributed to the inhibitory actions of $\mathbf{1}$, which might explain its greater potency than aspirin. Isosorbide, salicylic acid, isosorbide-2,5-disalicylate and isosorbide-5-salicylate (see Figure 1b) were incubated in PRP in the concentration range $10-300 \mu \mathrm{M}$ before triggering aggregation. None of the hydrolysis products significantly inhibited aggregation induced by collagen $(5 \mu \mathrm{g} / \mathrm{ml})(n=3$ at 11 concentration levels). The compounds were also co-incubated in the presence of aspirin to see if they potentiated its actions (either pharmacologically or by affecting disposition). None of the compounds affected aspirin's activity apart from isosorbidedisalicylate, which trended non-significantly towards an attenuation of aspirin's inhibitory effect (maximally 10\%) when co-incubated in the range 50-500 $\mu \mathrm{M}$.

\section{Influence of 1H-[1,2,4]oxadiazolo[4,3-a]quinoxalin-1-one on inhibition of aggregation induced by aspirin prodrugs}

The nitrates 3 and $\mathbf{4}$ were significantly more potent than aspirin and the other aspirin prodrugs ( 1 and 2 ) at inhibiting
ADP $(10 \mu \mathrm{M})$-induced platelet aggregation. To determine whether NO played a role in this effect, the irreversible guanyl cyclase inhibitor ODQ was pre-incubated with PRP in the aggregometer for $5 \mathrm{~min}$ before the addition of aspirin or aspirin prodrugs. Platelet aggregation was then initiated by the addition of ADP $(10 \mu \mathrm{M})$. ODQ caused a small but significant attenuation of the inhibitory action of nitrate 3 (Figure 3c). ODQ caused some inhibition when incubated alone with ADP and it increased the inhibition of ADPinduced platelet aggregation by aspirin, 1 and 2 .

\section{Effect of physostigmine on platelet aggregation inhibition}

The test compounds and aspirin were incubated in PRP at the maximally effective concentration of $300 \mu \mathrm{M}$ to inhibit collagen-induced aggregation in the presence or absence of $10 \mu \mathrm{M}$ physostigmine (eserine). This concentration level was separately shown to cause complete inhibition of plasma BuChE. All of the PRP experiments were conducted in samples that had normal BuChE levels (there are several polymorphisms leading to low BuChE activity). Physostigmine addition resulted in an almost complete loss of inhibitory activity of all of the test compounds (Figure 4) in PRP. In contrast, physostigmine did not exert a significant effect on inhibition of aggregation afforded by aspirin. In WP suspension physostigmine did not affect the inhibitory actions of the prodrugs or aspirin towards collagen-induced aggregation (Figure 4).

\section{Expression of platelet surface glycoproteins}

The activation of glycoprotein integrin receptor GPIIb/IIIa is crucial for platelet aggregation to occur. ${ }^{[31-33]}$ In addition the 

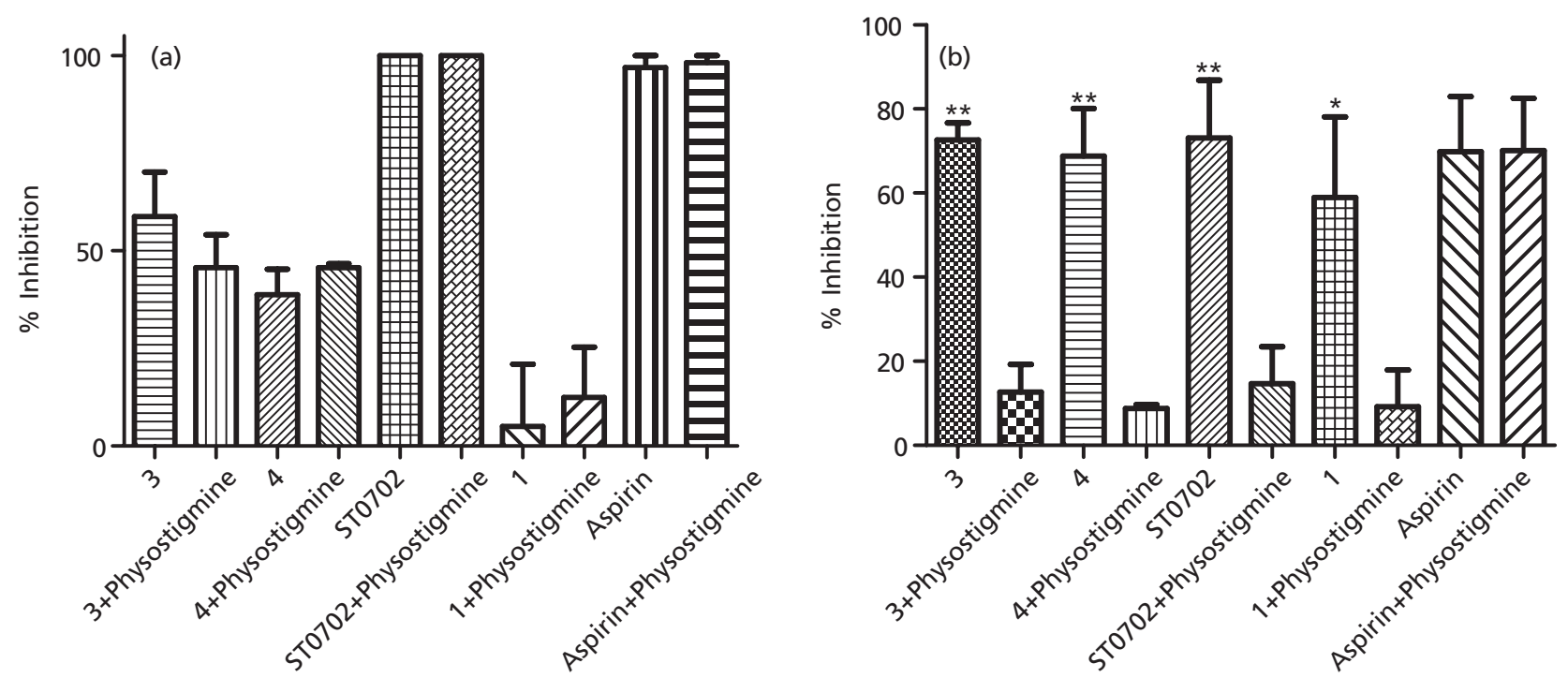

Figure 4 Inhibition (\%) of platelet aggregation in response to collagen $(5 \mu \mathrm{g} / \mathrm{ml}$ ) in the absence and presence of physostigmine (eserine) (10 $\mu \mathrm{M})$, an inhibitor of human plasma butyrylcholinesterase (BuChE). (a) Result of experiments in washed platelets (WP). (b) Results of experiments in platelet-rich plasma (PRP).
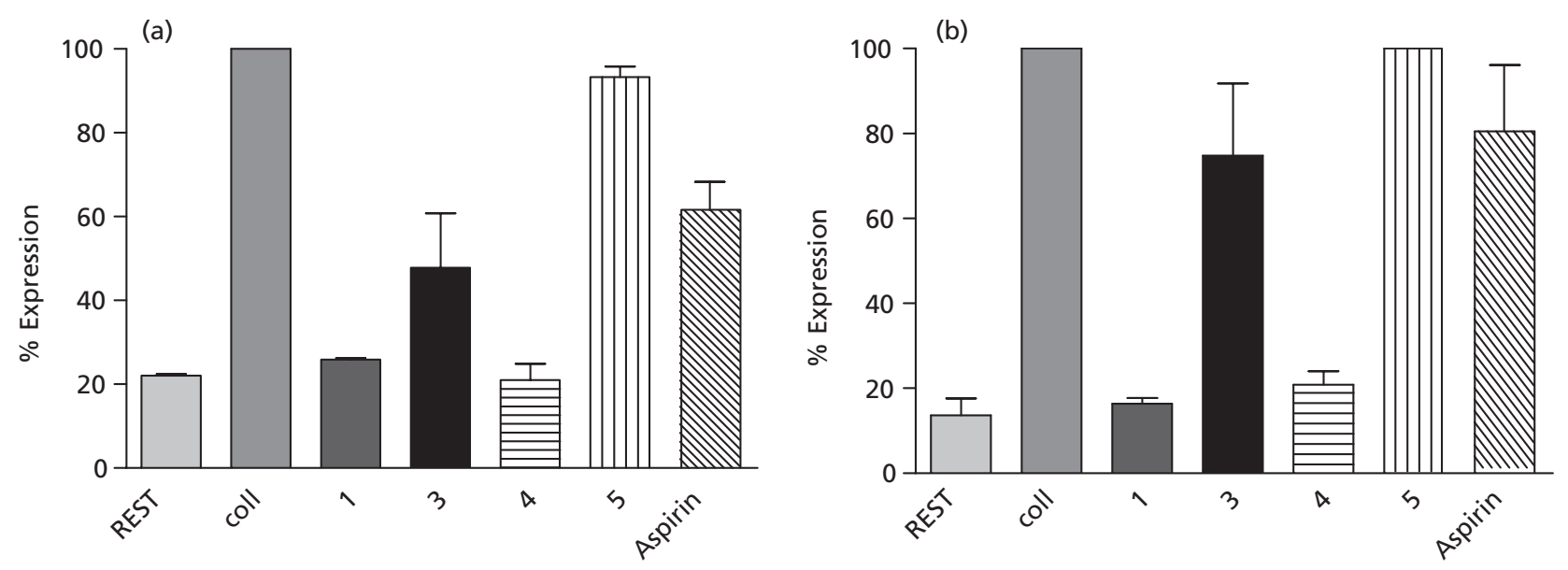

Figure 5 Effects of $\mathbf{1}, \mathbf{3}, \mathbf{4}, \mathbf{5}$ and aspirin at $60 \mu \mathrm{M}$ on platelet receptors P-selectin (5a) and GPIIb/Illa (5b) in PRP. Data are mean \pm SEM, $n=3$.

translocations of P-selectin from $\alpha$-granules to the platelet surface membrane underlie platelet adhesion. We measured the expression of these receptors following collagen stimulation in the presence of the test compounds at $60 \mu \mathrm{M}(n=3)$. As shown in Figure 5a and 5b, 1 and nitrate hybrid 4 suppressed activation of GPIIb/IIIa and translocation of P-selectin in PRP to resting levels but not in WP. Nitrate compound 5, which does not release aspirin in plasma, did not cause significant inhibition of either platelet marker in PRP or in WP. Compound 3 was equipotent with aspirin in PRP but not in WP. The effects overall were qualitatively similar to aspirin and they correlated with the known extent of aspirin generation in plasma solution (Table 1). U46619, a thromboxane mimetic, was used to investigate whether the prodrugs had any inhibitory effects downstream of thromboxane. Neither aspirin nor the aspirin prodrugs had any inhibitory effect on platelet aggregation induced by U46619 in PRP.

\section{Plasma and platelet esterase activity}

Plasma and platelet BuChE activity was measured using the Ellman assay ${ }^{[22]}$ with butyrylthiocholine (BTCI) and acetylthiocholine as substrate. NPA hydrolase activity was also determined since this substrate can be hydrolysed by CEs, which 
(a)
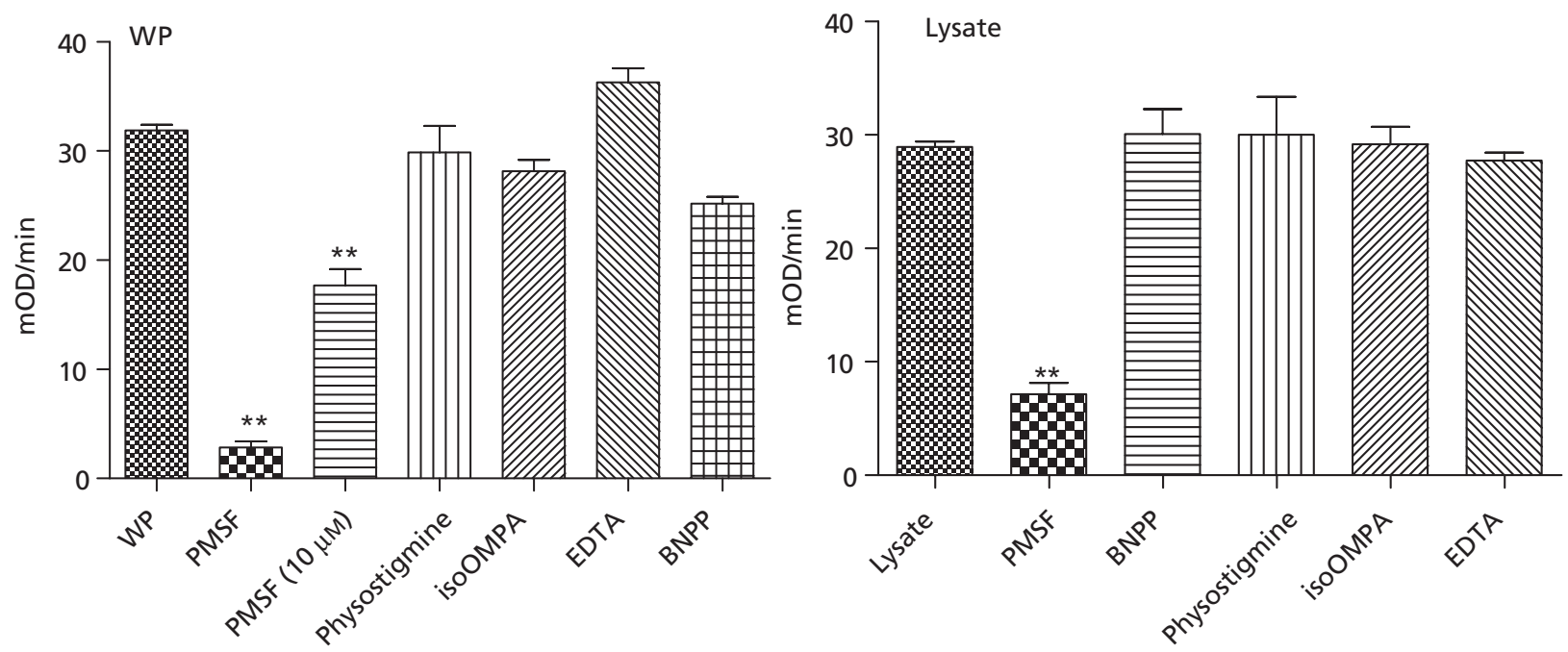

(b)
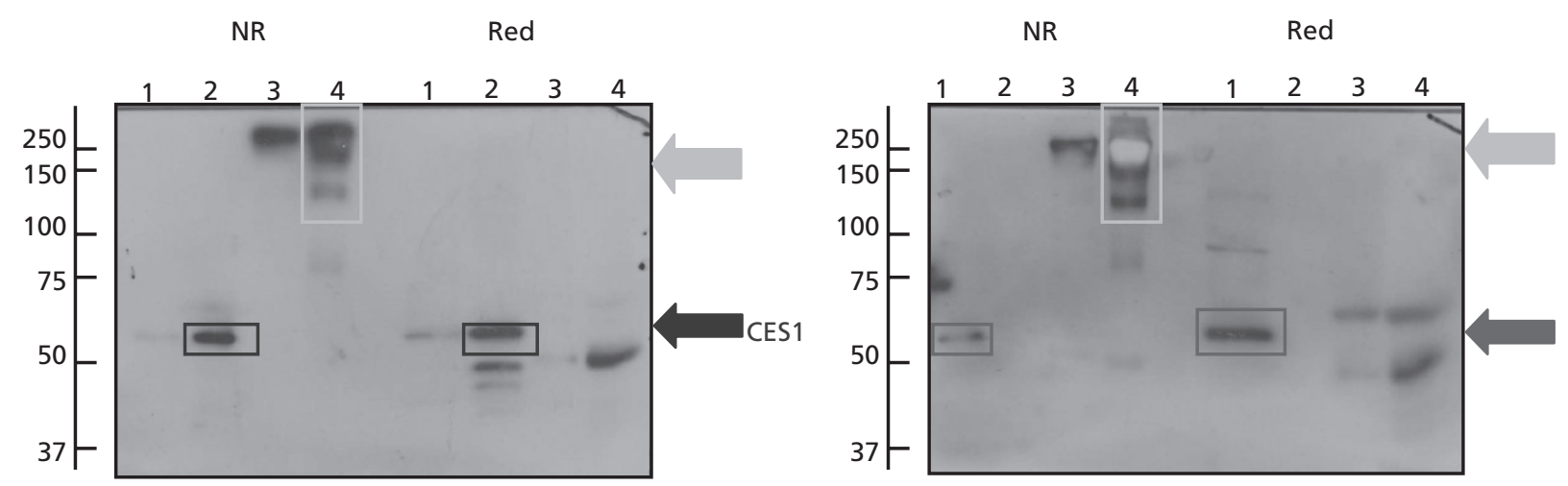
$1=$ Intestine
$2=$ Liver
$3=\mathrm{PPP}$
4=Platelets
$\mathrm{NR}=$ Non Reduced
Red=Reduced

Figure 6 (a) Effect of various esterase inhibitors on platelet turnover of $p$-nitrophenylacetate as reflected in change in optical density min $^{-1}$. (b) Western blot probing for CES-1 and CES-2 in human and liver intestinal microsomes, platelet poor plasma (PPP) and washed platelets (WP). PMSF, phenylmethylsulphonyl fluoride; BNPP, bis-p-nitrophylphosphate; IsoOMPA, tetraisopropylpyrophosphoramide; EDTA, ethylenediaminetetraacetic acid.

hydrolyse choline esters only slowly. BuChE activity in plasma and PRP was 6-9 $\mu_{\mathrm{M}}$ butyrylthiocholine $/ \mathrm{min} / \mathrm{ml}$. In contrast there was negligible esterase activity detectable in WP or washed platelet homogenate using the BuChE substrate. Weak activity (3-5 $\mu \mathrm{M} / \mathrm{min} / \mathrm{ml})$ was also detected in PRP and PPP using the substrate $p$ NPA. This was probably due to cholinesterase since there is little or no CE in human plasma. ${ }^{[34]}$ There was significant $p$ NPA hydrolysing activity in WP and in platelet lysate. As $p$ NPA hydrolysis activity could be due to
CE, BuChE, AChE or pPON esterases a series of inhibitors were used to classify the esterases present in the WP. Physostigmine, a cholinesterase inhibitor, ${ }^{[35,36]}$ caused a $25 \%$ reduction in pNPA hydrolysis activity of platelets. PMSF, a serine protease inhibitor, almost completely inhibited NPA activity in WP at concentration of $100 \mu \mathrm{M}$ and inhibited NPA activity by $50 \%$ at $10 \mu \mathrm{M}$ (Figure 6 ). EDTA, a calcium chelator that inhibits PON, ${ }^{[37]}$ had no effect on NPA activity of WP at concentrations up to $0.5 \mathrm{~mm}$. Iso-OMPA $(10-100 \mu \mathrm{M})$, a 
selective butrylcholinesterase inhibitor, ${ }^{[38]}$ had no effect on PNA activity of WP or lysed platelets. Surprisingly, BNPP $(10-100 \mu \mathrm{M})$, a specific CE inhibitor, ${ }^{[39]}$ had no significant effect on NPA activity of WP or lysed platelets. The NPA hydrolysis activity in the platelet suspension was not due to BuChE or PON esterases.

Probing platelet lysates run on nonreducing polyacrylamide gels with anti-CES1 and anti-CES2 antibodies, we observed bands with molecular weight in the range 150$400 \mathrm{kDa}$, not at the predicted molecular weight of $62 \mathrm{kDa}$ (Figure 6). These bands were similar in molecular weight to the bands observed by Oertel et al. ${ }^{[40]}$ by staining for alphaNA esterases. These bands appear to be a carboxylesterase type because of their cross reactivity with CES-1/2 antibody and ability to process $p$ NPA. When the gels were reduced these high-molecular-weight bands disappeared and were replaced by a doublet, with one band at $\sim 50 \mathrm{kDa}$ and another at $\sim 65 \mathrm{kDa}$ (Figure 6). WP suspensions were next treated with PMSF, before addition of ST0702 and platelet activating agent. PMSF attenuated the ability of ST0702 to inhibit platelet aggregation in a concentration dependent manner with maximal effects at $100 \mu \mathrm{M}$.

\section{Effect of phenylmethylsulphonyl fluoride on ST0702 platelet aggregation inhibition}

Of the prodrug compounds, 2 (ST0702) was the most efficacious inhibitor of collagen induced aggregation in WP (IC50 $154 \mu \mathrm{M})$. ST0702 had a greater than expected potency in WP where there is an absence of esterases responsible for the hydrolysis of these prodrugs in PRP. To determine if any PMSF-sensitive enzyme in platelets play a role in the hydrolysis of ST0702 in WP, PMSF was pre-incubated with WP at increasing concentrations up to $100 \mu \mathrm{M}$ for $5 \mathrm{~min}$, with stirring before the addition of ST0702 $(200 \mu \mathrm{M})$. Platelet aggregation was then initiated by addition of collagen $(2 \mu \mathrm{g} / \mathrm{ml})$. PMSF had no significant effect on collagen-induced aggregation. However PMSF $(100 \mu \mathrm{M})$ significantly attenuated the effect of ST0702 $(200 \mu \mathrm{M})$ on collagen-induced aggregation in WP (Figure 7). Lower amounts of PMSF (50 $\mu \mathrm{M}, 20 \mu \mathrm{M})$, also slightly attenuated the effect of ST0702 on collageninduced aggregation in WP, although this attenuation was not significant.

\section{Discussion}

This is the first pharmacological study into mechanisms of platelet inhibition by true aspirin prodrugs. The compounds in this study were previously reported to undergo productive processing generating aspirin in the presence of $\mathrm{BuChE}$ from human plasma. ${ }^{[6,7]}$ This is due to a particular fit for the BuChE active site that overrides the usual acetyl group preference for this enzyme, which prevents other aspirin esters from releasing

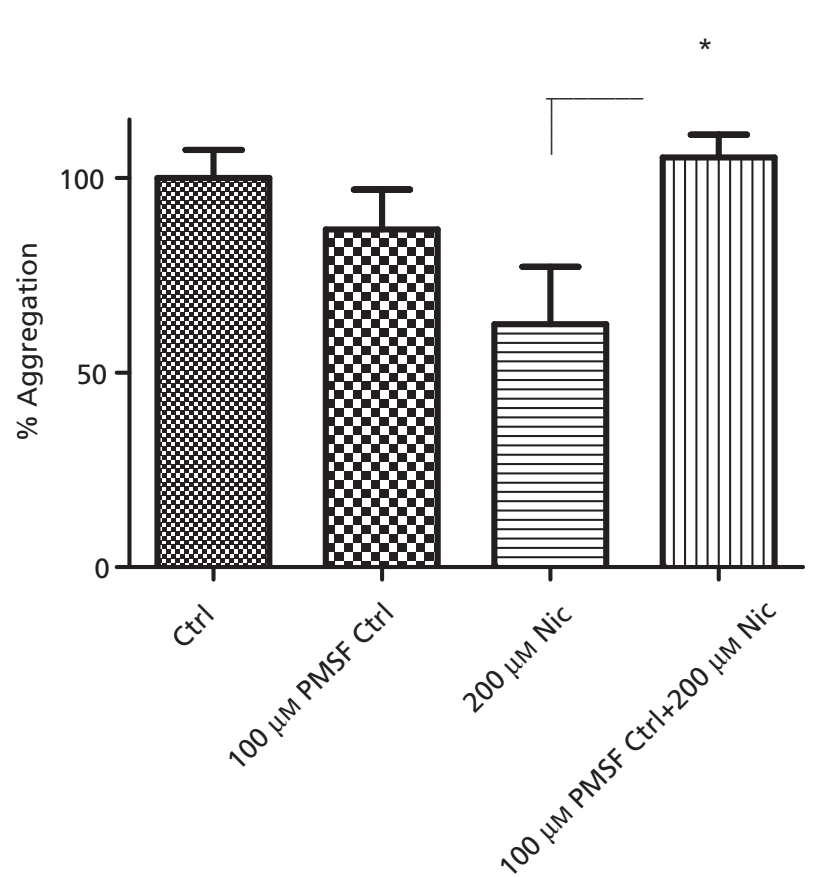

Figure 7 Effect of PMSF $(100 \mu \mathrm{M})$ on the inhibitory effect of ST0702 (Nic) $(200 \mu \mathrm{M})$ on platelet aggregation in response to collagen $(5 \mu \mathrm{g} / \mathrm{ml})$ in washed platelets (WP) $(n=4)$.

aspirin. The compounds are rapidly hydrolysed in plasma solution generating aspirin to $30-85 \%$ of the starting ester concentration. ${ }^{[6,7]}$ Compound $\mathbf{1}$ is the most effective aspirin prodrug ever discovered producing slightly less than a stoichiometric equivalent of aspirin. However, it is a significantly more potent inhibitor of platelet aggregation than aspirin. The platelet inhibitory properties of the nicotinate codrug ST0702 (2), which releases $<40 \%$ aspirin on a stoichiometric basis, have not been reported previously. In this study, ST0702 was equipotent with aspirin $(90 \mu \mathrm{M})$ in the inhibition of aggregation in PRP stimulated by collagen $(5 \mu \mathrm{g} / \mathrm{ml})$. The nitrate compounds $\mathbf{3}$ and $\mathbf{4}$ were reported to be more potent inhibitors of platelet aggregation in PRP than aspirin in response to collagen $(5 \mu \mathrm{g} / \mathrm{ml})$ and $\operatorname{ADP}(3 \mu \mathrm{M}){ }^{[6,7]}$ In this study we used a higher concentration of ADP to obtain a more reliable biphasic response to further probe the effect of the compounds on ADP-stimulated aggregation. Nitrate hybrid 5, which releases $<10 \%$ aspirin in solutions containing human plasma, was used in this study as a control to probe for the role of aspirin and $\mathrm{NO}$ release in the effects of in the NO-aspirin hybrids ( 3 and 4 ).

Several lines of evidence from this study indicate that the platelet inhibitory actions of the prodrugs 1-4 are substantially due to aspirin release: (i) compounds $\mathbf{1}$ and $\mathbf{2}$ were more potent or effective in PRP than in WP; (ii) their inhibitory actions in PRP were abrogated following pre-incubation with the cholinesterase inhibitor physostigmine; (iii) inhibition of collagen-induced aggregation in PRP by $200 \mu \mathrm{M} \mathbf{1}$ and 
ST0702 was time dependent (whereas aspirin's inhibitory effects were not); (iv) effects of the prodrugs on platelet GPIIb/IIIa and P-selectin expression were similar qualitatively to aspirin indicating that the inhibitory effects occurred upstream of receptor release/translocation; (v) the products of plasma esterase hydrolysis of $\mathbf{1}$ did not exert platelet inhibitory effects or modulate the platelet inhibitory properties of aspirin when co-incubated; (v) ester 5, which does not release aspirin, was not active.

Aspirin's failure to effectively inhibit ADP-induced aggregation is a clinically important deficiency of the drug which has prompted others to design aspirin-NO hybrids.

A number of these, including aspirin-furoxans, ${ }^{[41]}$ aspirindiazeniumdiolates $^{[42]}$ and aspirin-nitrates, ${ }^{[43]}$ have been studied in vitro as platelet aggregation inhibitors. The furoxans inhibit platelet aggregation in PRP mainly through NO release ${ }^{[41]}$ since this hybrid type is exclusively hydrolysed at the acetyl ester in media containing human plasma. ${ }^{[44]}$ The nitrate ester NCX-4016 does not inhibit platelet aggregation in PRP. ${ }^{[41]}$ It inhibits platelet aggregation in $\mathrm{WP}^{[45]}$ but in an NO and cGMP independent manner. ${ }^{[4]}$ NCX-4016 inhibits purified COX preparations by direct interaction (i.e. direct acyl transfer onto COX). ${ }^{[46]}$ This ability is lost in media containing human plasma because of a more rapid deacetylation by BuChE than transacetylation of COX. Inhibition of platelet aggregation with NCX-4016 is therefore only observed in WP where esterase levels are low.

The use of organic nitrates in alleviating the symptoms of angina has its mechanistic basis in NO release from endothelial and smooth muscle cells. ${ }^{[4]}$ Platelets are able to stimulate NO release from organic nitrates ${ }^{[48]}$ but much less effectively than smooth muscle cells. ${ }^{[49]} \mathrm{NO}$ has a well characterised endogenous role in gastric mucosal protection and preservation of mucosal defence is a general property of organic nitrate drugs. While organic nitrates produce insufficient NO locally to affect platelet aggregation, they have potential to mimic or augment its endogenous protective role in the intestinal mucosa.

Whereas collagen-induced aggregation at submaximal concentrations depends predominantly on the production of $\mathrm{TXA}_{2}$, it is highly susceptible to inhibition by COX inhibitors such as aspirin. ADP addition to platelet suspension produces a biphasic aggregation profile. The first phase of ADPinduced aggregation is independent of $\mathrm{TXA}_{2}$ production and hence COX inhibition (and thus resistant to aspirin). However the second phase of ADP-induced aggregation is dependent on the production of $\mathrm{TXA}_{2}$ and can be inhibited by COX inhibitors such as aspirin. We were interested to see if the NO-aspirin prodrugs retained the ability to inhibit the second (COX dependent) phase of ADP-induced aggregation while being able to dampen or reverse the COX-independent first phase. This could be useful in a disease situation where platelets are exposed to multiple pathophysiological stimuli.
The effect of $\mathbf{3}$ and $\mathbf{4}$ on ADP-induced aggregation was attenuated in the presence of the soluble guanyl cyclase inhibitor ODQ which blocks to some extent the platelet inhibitory effects of NO. ${ }^{[50]}$ In this study, ODQ itself partially inhibited platelet aggregation in response to collagen and it amplified the platelet inhibitory effects of the aspirin and prodrug 1 which does not produce NO. ODQ therefore had only a modest effect when co-incubated with the nitrate hybrids 3 and $\mathbf{4}$, because while it attenuated the effect of NO release it amplifed the aspirin effect. Overall, the evidence for a contribution from a NO-mediated effect from 3 and 4 derives from their inhibitory efficacy towards ADP-induced aggregation, as well as the observed reversal of the trend towards increased inhibition when aspirin and its prodrugs were co-incubated with ODQ.

Interestingly, the inhibitory effects of $\mathbf{3}$ and $\mathbf{4}$ in ADPinduced aggregation were abolished in the presence of physostigmine, which blocks aspirin release in PRP (data not shown). Compound 5, which releases NO but little aspirin, was not effective as an inhibitor of ADP-induced aggregation. These observations imply that aspirin and NO were acting synergistically in causing the inhibitory effects of $\mathbf{3}$ and $\mathbf{4}$.

The other outstanding question in this study was the greater than expected potency of the ester compounds and the significant inhibitory actions in WP suspension of 1 and ST0702 where BuChE was absent. We showed that BuChE is not relevant to the inhibitory actions of ST0702 in WP because the inhibitory effect was not abolished by pretreatment with physostigmine. A possible explanation for this was that the compounds were taken up by platelets and activated by a platelet esterase, possibly a CE. We therefore profiled the esterase activity in PRP, PPP, WP and platelet lysate using a range of substrate and esterase specific inhibitors. As expected, significant BuChE activity was detected in PRP and PPP but weak CE and AChE activity. Platelets are reported to possess a low level of BuChE activity, possibly plasma derived but trapped in the platelet canalicular system. A platelet membrane-associated AChEactivity has also been reported. ${ }^{[51]}$ These reports are consistent with our observation of weak WP and lysate turnover of the appropriate thiocholine esters. Several $\alpha$-naphthyl acetate ( $\alpha$ NA) hydrolysing esterases have been separated from platelets ${ }^{[40]}$ although platelet $\alpha \mathrm{NA}$ was reported to be resistant to inhibition by PMSF. ${ }^{[52]}$ Our results show that there is a multimeric protein in platelets that produces reduced fragments in the range 50-60 kD with high immunoreactivity towards human CES-1 and CES-2. These proteins are presumed to be the enzyme(s) catalysing the hydrolysis of CE substrate $p$ NPA. The platelet hydrolytic activity was blocked by the general serine esterase/protease inhibitor PMSF $(50-100 \mu \mathrm{M})$. The inhibitory activity of ST0702 $(200-300 \mu \mathrm{M})$ in WP was abolished when the suspension was pretreated with PMSF $(100 \mu \mathrm{M})$ indicating that a PMSF-sensitive enzyme in platelets causes the activation of ST0702 in WP. 
The result has significance for the potential utility of the compound for it (i) shows that the compound could be activated and cause platelet inhibition in a patient with low plasma esterase activity; (ii) shows that ST0702 does not possess intrinsic anti-platelet activity and, (iii) raises the prospect of increased cellular uptake and intracellular activation, potentially increasing potency. Despite releasing only $30-40 \%$ aspirin in PPP relative to a stoichiometric amount of aspirin, ST0702 has similar anti-platelet activity with respect to stimulation with ADP or collagen. The ester prodrugs are significantly more lipophilic than aspirin at $\mathrm{pH} 7.4$ as reflected in RP-HPLC retention and as expected from abrogation of the carboxylate. A plausible explanation for their high potency in PRP is that they partition into the platelet membrane to a greater extent than aspirin from where they undergo activation mediated by esterases at the platelet surface or intracellularly, producing locally high concentrations of aspirin. Enhanced cellular uptake would be interesting to investigate in other pathologically relevant cell types.

\section{Conclusions}

Inhibition of platelet aggregation by aspirin prodrugs $\mathbf{1 - 4}$ is primarily due to aspirin release. In the case of nitrate- substituted compounds inhibitory effects are due to release of both NO and aspirin with promising effects on ADP-induced aggregation. ST0702, a nicotinic acid-aspirin prodrug is activated by a PMSF-sensitive platelet esterase in WP platelet suspensions. Its unexpected potency in PRP may be due to platelet uptake and drug release. Thus, aspirin prodrugs effectively inhibit human platelet aggregation and as such may be an alternative to conventional aspirin.

\section{Declarations \\ Conflict of interest}

The Author(s) declare(s) that they have no conflicts of interest to disclose.

\section{Funding}

M.W.R. is supported by Science Foundation Ireland (SFI), C.M. is an SFI Stokes lecturer. The work was funded by Enterprise Ireland under the Technology Development Program (TD2007120) and by Solvotrin Therapeutics LTD, Cork, Ireland.

\section{References}

1. Nielsen NM, Bundgaard H. Evaluation of glycolamide esters and various other esters of aspirin as true aspirin prodrugs. J Med Chem 1989; 32: 727-734.

2. Anand BS et al. Phospholipid association reduces the gastric mucosal toxicity of aspirin in human subjects. Am J Gastroenterol 1999; 94: 1818-1822.

3. Lichtenberger LM. Where is the evidence that cyclooxygenase inhibition is the primary cause of nonsteroidal antiinflammatory drug (NSAID)-induced gastrointestinal injury? Topical injury revisited. Biochem Pharmacol 2001; 61: 631-637.

4. Hankey GJ, Eikelboom JW. Aspirin resistance. BMJ 2004; 328: 477-479.

5. Tran HA etal. Aspirin resistance. Thromb Res 2007; 120: 337-346.

6. Moriarty LM et al. Discovery of a 'true' aspirin prodrug. J Med Chem 2008; 51: 7991-7999.

7. Jones $\mathrm{M}$ et al. Isosorbide-based aspirin prodrugs: integration of nitric oxide releasing groups. J Med Chem 2009; 52: 6588-6598.

8. Ahmed MH. What does the future hold for niacin as a treatment for hyperlipidaemia and cardiovascular disease? J Cardiovasc Med (Hagerstown) 2010; 11 : 858-860.

9. Asztalos BF. High-density lipoprotein particles, coronary heart disease, and niacin. J Clin Lipidol 2010; 4: 405410.

10. Nordestgaard BG et al. Lipoprotein(a) as a cardiovascular risk factor: current status. Eur Heart J 2010; 31: 2844-2853.

11. Radomski MW etal. Comparative pharmacology of endothelium-derived relaxing factor, nitric oxide and prostacyclin in platelets. Br J Pharmacol 1987; 92: 181-187.

12. Radomski MW etal. Endogenous nitric oxide inhibits human platelet adhesion to vascular endothelium. Lancet 1987; 2: 1057-1058.

13. Radomski MW etal. The role of nitric oxide and cGMP in platelet adhesion to vascular endothelium. Biochem
Biophys Res Commun 1987; 148: $1482-$ 1489.

14. Fiorucci $S$ et al. Interaction of a selective cyclooxygenase-2 inhibitor with aspirin and NO-releasing aspirin in the human gastric mucosa. Proc Natl Acad Sci USA 2003; 100: 10937-10941.

15. Perini $\mathrm{R}$ et al. Mechanisms of nonsteroidal anti-inflammatory druginduced gastrointestinal injury and repair: a window of opportunity for cyclooxygenase-inhibiting nitric oxide donors. Can J Gastroenterol 2004; 18: 229-236.

16. Wallace JL etal. Aspirin, but not NO-releasing aspirin (NCX-4016), interacts with selective COX-2 inhibitors to aggravate gastric damage and inflammation. Am J Physiol Gastrointest Liver Physiol 2004; 286: G76-G81.

17. Lazzarato L et al. (Nitrooxyacyloxy)methyl esters of aspirin as novel nitric oxide releasing aspirins. $J$ Med Chem 2009; 52: 5058-5068.

18. Radomski M, Moncada S. An improved method for washing of human platelets 
with prostacyclin. Thromb Res 1983; 30: 383-389.

19. Jurasz $\mathrm{P}$ et al. Matrix metalloproteinase 2 in tumor cell-induced platelet aggregation: regulation by nitric oxide. Cancer Res 2001; 61: 376-382.

20. Radomski A et al. Nanoparticleinduced platelet aggregation and vascular thrombosis. Br J Pharmacol 2005; 146: 882-893.

21. Medina $\mathrm{C}$ et al. Platelet aggregationinduced by caco- 2 cells: regulation by matrix metalloproteinase-2 and adenosine diphosphate. J Pharmacol Exp Ther 2006; 317: 739-745.

22. Ellman GL et al. A new and rapid colorimetric determination of acetylcholinesterase activity. Biochem Pharmacol 1961; 7: 88-95.

23. Abrams CS et al. Direct detection of activated platelets and platelet-derived microparticles in humans. Blood 1990; 75: 128-138.

24. Radomski A et al. Pharmacological characteristics of solid-phase von Willebrand factor in human platelets. $\mathrm{Br} \mathrm{J}$ Pharmacol 2001; 134: 1013-1020.

25. Jurasz $\mathrm{P}$ et al. Role of von Willebrand factor in tumour cell-induced platelet aggregation: differential regulation by NO and prostacyclin. Br J Pharmacol 2001; 134: 1104-1112.

26. Chung AW et al. Mechanisms of action of proteinase-activated receptor agonists on human platelets. Br J Pharmacol 2002; 135: 1123-1132.

27. Laemmli UK et al. Correlation between structural transformation and cleavage of the major head protein of T4 bacteriophage. Cell 1976; 7: 191-203.

28. Towbin $\mathrm{H}$ et al. Electrophoretic transfer of proteins from polyacrylamide gels to nitrocellulose sheets: procedure and some applications. Proc Natl Acad Sci USA 1979; 76: 4350-4354.

29. Lee $S$ et al. Protein binding of acetylsalicylic acid and salicylic acid in porcine and human serum. Vet Hum Toxicol 1995; 37: 224-225.

30. Liyasova MS et al. Reaction of human albumin with aspirin in vitro: mass spectrometric identification of acetylated lysines 199, 402, 519, and 545. Biochem Pharmacol 2010; 79: 784-791.
31. Coller BS. Blockade of platelet GPIIb/ IIIa receptors as an antithrombotic strategy. Circulation 1995; 92: 23732380.

32. Coller BS. The role of platelets in arterial thrombosis and the rationale for blockade of platelet GPIIb/IIIa receptors as antithrombotic therapy. Eur Heart J 1995; 16(Suppl. L): 11-15.

33. Coller BS et al. The anti-GPIIb-IIIa agents: fundamental and clinical aspects. Haemostasis 1996; 26(Suppl. 4): 285-293.

34. Li B et al. Butyrylcholinesterase, paraoxonase, and albumin esterase, but not carboxylesterase, are present in human plasma. Biochem Pharmacol 2005; 70: 1673-1684.

35. Myers DK, Mendel B. Investigations on the use of eserine for the differentiation of mammalian esterases. Proc Soc Exp Biol Med 1949; 71: 357-360.

36. Ogura $\mathrm{H}$ et al. Comparison of inhibitory activities of donepezil and other cholinesterase inhibitors on acetylcholinesterase and butyrylcholinesterase in vitro. Methods Find Exp Clin Pharmacol 2000; 22: 609-613.

37. Golmanesh L et al. Simple procedures for purification and stabilization of human serum paraoxonase-1. J Biochem Biophys Methods 2008; 70: 1037-1042.

38. Grubic $\mathrm{Z}$ et al. Iso-OMPA-induced potentiation of soman toxicity in rat correlates with the inhibition of plasma carboxylesterases. Arch Toxicol 1988; 62: 398-399.

39. Khan D et al. Pharmacological effects of a novel isosorbide-based butyrylcholinesterase inhibitor. Chem Biol Interact 2008; 175: 231-234.

40. Oertel J et al. Alpha naphthyl acetate esterase in human blood cells with different molecular weights. Blut 1983; 46: 101-106.

41. Turnbull CM et al. Mechanism of action of novel NO-releasing furoxan derivatives of aspirin in human platelets. BrJ Pharmacol 2006; 148: 517-526.

42. Chattopadhyay $\mathrm{M}$ et al. Comparison between 3-Nitrooxyphenyl acetylsalicylate (NO-ASA) and O2-(acetylsalicyloxymethyl)-1- (pyrrolidin-1-yl)diazen-1-ium-1,2diolate (NONO-ASA) as safe antiinflammatory, analgesic, antipyretic, antioxidant prodrugs. J Pharmacol Exp Ther 2010; 335: 443-450.

43. Lechi $\mathrm{C}$ et al. The antiplatelet effects of a new nitroderivative of acetylsalicylic acid-an in vitro study of inhibition on the early phase of platelet activation and on TXA2 production. Thromb Haemost 1996; 76: 791-798.

44. Cena Cet al. Antiinflammatory, gastrosparing, and antiplatelet properties of new NO-donor esters of aspirin. J Med Chem 2003; 46: 747-754.

45. Lechi $\mathrm{C}$ et al. In vitro study of the antiaggregating activity of two nitroderivatives of acetylsalicylic acid. Blood Coagul Fibrinolysis 1996; 7: 206-209.

46. Corazzi T et al. Direct and irreversible inhibition of cyclooxygenase-1 by nitroaspirin (NCX 4016). J Pharmacol Exp Ther 2005; 315: 1331-1337.

47. Feelisch M. Biotransformation to nitric oxide of organic nitrates in comparison to other nitrovasodilators. Eur Heart J 1993; 14(Suppl. I): 123-132.

48. Weber AA et al. Biotransformation of glyceryl trinitrate by blood platelets as compared to vascular smooth muscle cells. Eur J Pharmacol 1996; 309: 209213.

49. Weber AA et al. Direct inhibition of platelet function by organic nitrates via nitric oxide formation. Eur J Pharmacol 1993; 247: 29-37.

50. Moro MA et al. cGMP mediates the vascular and platelet actions of nitric oxide: confirmation using an inhibitor of the soluble guanylyl cyclase. Proc Natl Acad Sci USA 1996; 93: 1480 1485.

51. Nachman RL, Ferris B. Studies on the proteins of human platelet membranes. J Biol Chem 1972; 247: 44684475.

52. Dufer J et al. Differential effect of the serine protease inhibitor phenyl methyl sulfonyl fluoride on cytochemically detectable esterases in human leucocytes and platelets. Scand J Haematol 1984; 32: 25-32. 